\title{
Projeto político pedagógico:elaboração e aplicação nas escolas públicas de maringá
}

\author{
Amauri Aparecido Bássoli* \\ Ana Luiza Barbosa Anversa ** \\ Fabiane Castilho Teixeira*** \\ Nadia Maria Qualio Braz ${ }^{* * * *}$
}

\begin{abstract}
Resumo: Essa pesquisa objetivou compreender como ocorre a participação da equipe pedagógica e comunidade de vinte escolas públicas de Maringá, no processo de elaboração e aplicação do projeto político pedagógico. Os instrumentos de análise utilizados foram arquivos documentais, e entrevista semi-estruturada com a equipe pedagógica, professores de Educação Física e das demais disciplinas. Constatou-se um paradoxo entre a elaboração e aplicação do projeto político pedagógico no ambiente escolar. Professores e equipe pedagógica afirmam ter conhecimento acerca das suas especificidades e contribuições, mas, a sistematização e aplicabilidade se tornam inconsistentes, ou, inexistentes, mediante as diversidades e dificuldades apresentadas no contexto.

Palavras chave: Formulação de projetos. Educação. Autonomia profissional.
\end{abstract}

\section{INTRODUÇÃo}

O projeto político pedagógico (PPP) configura-se como a sistematização de um planejamento participativo, no qual se define a ação educativa que será realizada na caminhada pedagógica. Vasconcellos (2005) define como "[...] um instrumento teórico-metodológico para a intervenção e mudança da realidade". Sua elaboração constitui a base de todo trabalho a ser desenvolvido no contexto escolar, tido como

\footnotetext{
* Docente do Programa de Mestrado em Educação Física pelo Programa de Pós Graduação Associado UEM / UEL. Maringá, PR, Brasil. e-mail: amauribassoli@gmail.com

** Mestre em Educação Física pelo Programa de Pós Graduação Associado UEM / UEL. Maringá, PR, Brasil. e- mail: ana.beah@gmail.com

*** Mestranda do Programa de Pós-Graduação Associado em Educação Física- UEM/UEL. Maringá, PR, Brasil. e-mail: fabt.ct@hotmail.com

**** Acadêmica em Educação Física, pela Universidade Estadual de Maringá (UEM).

Maringá, PR, Brasil. e-mail: nadiaqualio@hotmail.com
} 
um dos grandes desafios para gestores e professores. Analisando as dadas incumbências, questiona-se, o que é PPP?

No sentido etimológico, o termo projeto vem do latim projectu, particípio passado do verbo projice$r e$, que significa lançar para diante. Plano, intento, desígnio. Empresa, empreendimento. Redação provisória de lei. Plano geral de identificação. (FERREIRA, $1975^{1}$ apud VEIGA, 1995, p.12)

Mello (2004) apresenta duas faces indissolúveis do PPP. É político, por estar associado a compromissos sociopolíticos e a interesses reais e coletivos da população, no sentido de formação de cidadãos para a sociedade. E pedagógico, por definir as ações educativas e características necessárias às escolas, para cumprirem seus propósitos e intencionalidade.

O PPP, então deve ser entendido como um projeto de reflexão, em busca da qualidade do sistema de ensino. As alternativas de melhorias são necessárias e a participação dos membros da comunidade escolar é indispensável. Segundo Veiga (1995, p.14):

\begin{abstract}
A principal possibilidade de construção do PPP passa pela relativa autonomia da escola, de sua capacidade de delinear sua própria identidade. Isto significa resgatar a escola como espaço público, lugar de debate, de diálogo, fundado na reflexão coletiva. Portanto, é preciso entender que o PPP da escola dará indicações necessárias à organização do trabalho pedagógico, que inclui o trabalho do professor na dinâmica interna da sala de aula.
\end{abstract}

Em 1996, a Lei de Diretrizes e Bases da Educação Nacional (LDBEN) n. 9.394 legitimou que os estabelecimentos de ensino teriam a incumbência de "[...] elaborar e executar sua própria proposta pedagógica" (BRASIL, 1996). Mello (2004) salienta que com a promulgação desta lei as preocupações pedagógicas foram resgatadas em um novo contexto, dando as escolas uma autonomia mais concreta, na qual o espaço escolar é democratizado e as ações interventivas são

\footnotetext{
${ }^{1}$ FERREIRA, A.B.H. Novo dicionário da língua portuguesa. Rio de Janeiro. Nova Fronteira 1975.

Movimento, Porto Alegre, v. 17, n. 01, p. 77-94, janeiro/março de 2011.
} 
elaboradas sob um contexto que engloba a comunidade "para além dos muros da escola" permitindo o surgimento de uma sociedade na qual a cultura e os valores são preservados e ensinados.

Neste sentido Freire (2002) ressalta que o planejamento educacional deve responder às marcas e valores de uma determinada sociedade, preservando formas de cultura e interferindo no processo histórico. Faz-se necessária também uma construção coletiva de conhecimentos com tentativa de resgatar o sentido humano, científico e libertador do planejamento, não podendo ficar apenas no campo filosófico.

Baseada no princípio do direito universal à educação para todos, a LDBEN de 1996 apresentou mudanças em relação às leis anteriores. Introduziu a inclusão da educação infantil como primeira etapa da educação básica, o processo de avaliação e gerenciamento da informação educacional, a consagração da autonomia, bem como passou a valorizar a proposta pedagógica da instituição escolar.

No bojo desta lei, notadamente, nos artigos 12 e 13, encontram-se importantes menções acerca da proposta pedagógica. $\mathrm{O}$ artigo 12 traz que os estabelecimentos de ensino terão a incumbência de elaborar e executar sua proposta pedagógica, bem como velar pelo cumprimento do plano de trabalho de cada docente e articular-se com as famílias e com a comunidade. No que se refere aos docentes, o artigo 13 coloca que terão a responsabilidade de participar da elaboração da proposta pedagógica do estabelecimento de ensino; elaborar e cumprir os planos de trabalho; zelar pela aprendizagem dos alunos; estabelecer estratégias de recuperação para os alunos de menor rendimento; ministrar os dias letivos e horas-aula estabelecidos e articular atividades da escola com a família e com a comunidade.

Por meio desta lei, a Educação Física, busca pela sua identidade e reconhecimento. Moreira (2004) salienta que com a lei e respaldo dos Parâmetros Curriculares Nacional de 1998, a Educação Física passou de atividade para componente curricular, considerada importante na construção de uma cultura reflexiva, na qual o físico e a aptidão não é mais requisito básico para acesso aos seus conhecimentos.

Movimento, Porto Alegre, v. 17, n. 01, p. 77-94, janeiro/março de 2011. 
Começou-se a se organizar/sistematizar aulas com um desenvolvimento diferenciado, com conteúdos voltados para os conhecimentos corporais culturais, se apoiando para além das ciências médicas e práticas desportivas, na antropologia social. Nas palavras de Silveira e Pinto (2001), a Educação Física se justifica na escola, uma vez que não há outra prática pedagógica que se ocupe da dimensão cultural de que só essa área do conhecimento trata que é a cultura do movimento humano, expressa nos jogos e brincadeiras, lutas, danças, esportes e ginásticas.

A partir de então, os professores da área buscam inserir-se na participação de discussões voltadas para princípios éticos políticos e sociais. A Educação Física é uma disciplina que possibilita o aluno extrapolar possibilidades determinadas, sem delimitação de paredes e carteiras, por isso, com base em Bartholo (2000), com princípios de liberdade, cooperação e responsabilidade é possível se formar um sujeito autônomo, que pode experimentar diferentes papéis na aula e essa experiência, própria de suas possibilidades disciplinares dá ao professor suporte para debater questões de planejamento, execução, avaliação e intervenção junto à equipe pedagógica, definidos por meio do PPP da instituição.

A elaboração e aplicação do PPP se colocam como necessidade social e educacional. Ao se apresentarem, exclusivamente, como documentos formais dentro da escola passam a não assumir sua representatividade. Em muitos casos, o grupo educacional reluta em perceber a importância de se elaborar e concretizar o planejamento pedagógico.

Diante disso, verificou-se junto à comunidade educacional pública de Maringá, como o PPP vem sendo entendido e considerado no cotidiano das aulas, buscando compreender como ocorre a participação da equipe escolar e da comunidade, no processo de elaboração e aplicação, meio pelo qual se concretiza as propostas idealizadas.

A partir desses apontamentos, questiona-se: como as escolas públicas de Maringá organizam e aplicam os PPP's? Como os professores de Educação Física consideram e aplicam os PPP's em suas aulas?

Movimento, Porto Alegre, v. 17, n. 01, p. 77-94, janeiro/março de 2011. 


\section{Metodologia}

O presente estudo se caracteriza como qualitativo do tipo descritivo. Miles e Huberman, (1994) salientam que esta metodologia, oferece descrições ricas sobre a realidade tornando-se possível selecionar, analisar e interpretar dados de campo em contraponto a concepções iniciais, traçando explicações ricas de um contexto específico.

A rede pública de ensino do Município é composta por 70 escolas, sendo 38 municipais e 32 estaduais. A amostra foi composta por $30 \%$ das escolas de cada rede, sendo assim, participaram do estudo, vinte escolas públicas, sendo nove estaduais e 11 municipais.

Em cada uma das instituições de ensino integrantes da amostra foram sorteados, a partir da listagem do corpo docente, três professores para participar da coleta dos dados em cada escola, sendo um da equipe pedagógica gestora, um da educação física e um das demais disciplinas, totalizando 60 professores.

Os dados pertinentes a pesquisa foram coletados por meio de análise documental dos PPP's e roteiro de entrevista semiestruturada, elaborada pelos autores da pesquisa, e aplicada em um participante de cada segmento. Este instrumento teve por objetivo permitir que o entrevistado desenvolva espontaneamente sua linha de pensamento, trilhando o caminho principal colocado pelo investigador. (TRIVIÑOS, 1987).

Em seguida foram discutidos e tratados com base na metodologia de análise de conteúdo proposta por Bardin (1977, p. 38), entendida "[...] como um conjunto de técnicas de análise das comunicações, que utiliza procedimentos sistemáticos e objetivos de descrição do conteúdo das mensagens". Esta metodologia permitiu que os dados fossem agrupados em categorias por similaridade, facilitando a triangulação dos dados e interpretações pertinentes.

Ressalta-se por fim, que os participantes assinaram o termo de consentimento livre e esclarecido dos sujeitos, que informa os objetivos do estudo e a forma de participação, e que a pesquisa foi aprovada pelo Comitê de Ética da Universidade Estadual de Maringá - COPEP, Parecer 0202.0.093.000-09.

Mavimento, Porto Alegre, v. 17, n. 01, p. 77-94, janeiro/março de 2011. 


\section{Resultados E discussões}

A realidade escolar se apresenta cada vez mais heterogênea, especialmente, no que se refere aos atores sociais que a compõem, haja vista que as relações dos sujeitos inseridos neste contexto ultrapassam os muros da instituição, o que resulta em uma maior influência de questões sociais e comunitárias na estruturação de políticas educacionais internas, como o PPP.

Essas questões alicerçam a construção da autonomia na escola, se fazendo necessário um planejamento e gestão democrática, no qual, a lei só vem a ser facilitadora da legitimidade. Diante disso, Pinheiro (1998) reforça que o PPP se faz instrumento de conquista da autonomia, e por meio de uma elaboração coletiva torna-se possível modificar a prática pedagógica conservadora vigente.

Analisando estes pontos com os dados coletados e triangulando com as contribuições do aporte teórico da temática em questão, percebe-se que o entendimento sobre o PPP e suas especificidades é bastante consistente. De modo geral, os entrevistados, entendem o PPP e suas necessidades dentro do contexto escolar, colocando-o como eixo norteador do fazer diário, sendo à base da vertente teórica que rege os fundamentos metodológicos, orientando como virá a ser desenvolvido o processo de avaliação e as atividades em sala de aula. Os depoimentos abaixo ilustram tal entendimento:

\footnotetext{
O PPP norteia todo o trabalho da escola, garantindo fundamentação teórica a metodologia, avaliação e as atividades a serem desenvolvidas. (Coordenação Pedagógica)

O projeto é a base que utilizamos para desenvolver nosso trabalho Sendo essencial dentro da escola e para o trabalho desenvolvido (Professor das demais áreas)
}

São as ações, objetivos e metas que a escola tem que alcançar, nas quais buscamos orientações para o nosso trabalho. (Professor de Educação Física)

Constata-se que os docentes atuantes, no ambiente escolar público de Maringá, demonstram sintonia com os aportes preconizados

Movimento, Porto Alegre, v. 17, n. 01, p. 77-94, janeiro/março de 2011. 
no documento, mas se deparam com dificuldades na extensão destes objetivos e idéias para o campo prático, não tendo um entendimento concreto das ferramentas proporcionadas para se atingir metas estabelecidas.

Essa situação fica evidente ao questionarmos como os docentes consideram o PPP no cotidiano das atividades que desenvolvem. A equipe pedagógica, em sua maioria, aponta o projeto como eixo orientador, no qual estruturas e ações interventivas são discutidas e direcionadas aos processos de avaliação e reflexão educativa. $\mathrm{O}$ apontamento que melhor explicita o posicionamento do grupo traz que o PPP é a forma de planejar e organizar as ações, adotando-se uma postura política e organizacional, desde a metodologia a ser adotada aos critérios de avaliação.

Já na visão dos docentes, a consideração do PPP no cotidiano escolar se apresenta, de certa forma, antagônica, pois, ao mesmo passo em que os professores demonstram um entendimento consistente sobre o PPP e suas contribuições, ao interrogarmos em relação à aplicabilidade, não obtivemos respostas concretas. De forma geral o grupo aponta que o PPP é o alicerce da escola, que dá o direcionamento das ações, no entanto, a efetivação deste planejamento é difícil de seguir.

Na mesma direção, o depoimento que melhor sintetiza o entendimento dos professores de Educação Física, aponta que:

\footnotetext{
O PPP é uma diretriz formulada junto à equipe pedagógica, que dá direção para atingir os objetivos dos alunos. Mas as estratégias adotadas têm que ser diferentes. Cada turma tem uma necessidade, então às vezes fica complicado seguir exatamente o que foi proposto, pois, temos que cumprir conteúdo.
}

Autores que debatem o assunto argumentam que este é um conflito comum, e que, se espera que o PPP não seja apenas um discurso atribuído ao processo educacional, mas sim, que se adotem ações interventivas, calcadas em princípios de organização do trabalho pedagógico e que atendam a todos os envolvidos no processo de ensino-aprendizagem. Contribuindo com a discussão Veiga (1991, p. 82) ressalta que:

Movimento, Porto Alegre, v. 17, n. 01, p. 77-94, janeiro/março de 2011. 
A importância desses princípios está em garantir sua operacionalização nas estruturas escolares, pois uma coisa é estar no papel, na legislação, na proposta, no currículo, e outra é estar ocorrendo na dinâmica interna da escola, no real, no concreto.

Com o entendimento do que vem a ser o PPP e as necessidades que deve atender, a comunidade escolar o coloca como um documento em permanente construção, pautado em discussões e reflexões acerca do cotidiano escolar, que para se fazer verdadeiramente interpretado, requer a participação de todos os envolvidos nesta relação.

De acordo com Mello (2004), para se abranger o contexto escolar é importante um bom conhecimento sobre a comunidade que o cerca, objetivando obter informações pontuais, como, por exemplo, investigar se é uma comunidade itinerante ou fixa; qual seu perfil socioeconômico e cultural; qual o nível de escolaridade, profissão e naturalidade dos alunos, assim como, suas condições de moradia, lazer e cultura. Tendo esses pontos analisados, é possível delinear o potencial da comunidade.

Tais, reflexões oportunizam o entendimento, de como desenvolver um trabalho, tendo por base as características dos alunos e os problemas que trazem, conjugando esforços na promoção da aprendizagem.

Sobre o assunto, Freire (2004) argumenta:

$$
\begin{aligned}
& \text { Por que não aproveitar a experiência que tem os } \\
& \text { alunos de viver em áreas da cidade descuidadas } \\
& \text { pelo poder público para discutir, por exemplo, a } \\
& \text { poluição dos riachos e dos córregos e os baixos } \\
& \text { níveis de bem estar da população, os lixões e os } \\
& \text { riscos que oferecem à saúde das gentes. }
\end{aligned}
$$

Diante de tantos apontamentos sobre a contribuição da construção coletiva do PPP, os atores envolvidos no processo apresentam opiniões que divergem parcialmente. De acordo com os dados coletados e ilustrados nas Figuras1 e 2, percebe-se que, muitas vezes, a formulação e estruturação do PPP não inclui todos os envolvidos no sistema educacional, acarretando divergências, quando se trata de conferir responsabilidade à sua elaboração.

Movimento, Porto Alegre, v. 17, n. 01, p. 77-94, janeiro/março de 2011. 


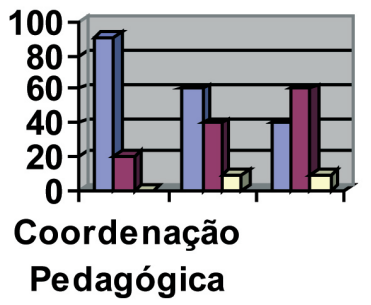

\begin{tabular}{|l|}
\hline$\square$ Com unidade \\
Escolar \\
\\
Equipe \\
Pedagógica + \\
Professores \\
$\square$ Equipe \\
Pedagógica
\end{tabular}

Figura 1: Atribuição de responsabilidade sobre a elaboração do PPP na opinião dos entrevistados das Escolas Municipais.

Com base na Figura 1, observa-se que para a coordenação pedagógica e professores de diversas disciplinas, a elaboração deve contar com a participação de toda comunidade escolar, ou seja, equipe pedagógica, professores, pais e alunos. Já para os professores de educação física da rede Municipal de ensino, há uma tendência de que o PPP deva ser elaborado pela equipe pedagógica e professores
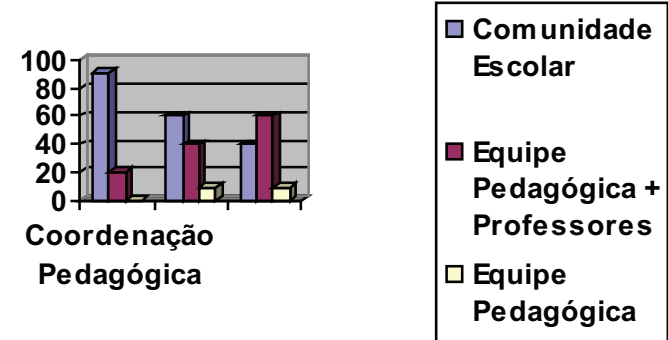

Figura 2: Atribuição de responsabilidade sobre a elaboração do PPP na opinião dos entrevistados das Escolas Estaduais.

Nas escolas Estaduais de Maringá (Figura 2) a situação é diversa. A equipe pedagógica e alguns docentes designam o papel de formulação e estruturação do PPP, em sua maioria, para a equipe pedagógica. E os professores de Educação Física apontam que deve

Movimento, Porto Alegre, v. 17, n. 01, p. 77-94, janeiro/março de 2011. 
ser estruturado pela comunidade escolar, dado inverso ao apontado pelos professores da rede municipal.

Subsidiando a discussão, Gadotti (1994), ressalta que o PPP deve ser construído por uma equipe interdisciplinar, envolvendo funcionários, educadores, alunos e pais, que definirão o tipo de sociedade e cidadão que pretendem formar. Em acordo, Marques (1995) defende que ao traçar sua proposta pedagógica no livre consenso dos interessados, se conduz a uma coordenação solidária e, conseqüentemente, com co-responsabilidade.

A Lei 9.394/96 ressalta no artigo n. 14, que a participação coletiva se coloca como essencial à gestão democrática, em que se torna imprescindível a participação de profissionais da educação e da comunidade escolar e local em conselhos escolares. Na instituição escolar é preciso realizar-se mediações práticas que, segundo Severino (2008), deve recomendar ações que permitam o entrecruzamento dos projetos coletivos da sociedade e dos projetos pessoais de educadores e educandos. $\mathrm{O}$ ato de planejar no tempo-espaço escolar significa, com base em Libâneo (1992, p.221), “[...] um processo de racionalização e coordenação da ação docente, articulando a atividade escolar e problemática do contexto social".

Como tal meio social passa por constantes mudanças, relacionadas, sobretudo, a aspectos de ordem socioeconômicos, o PPP também necessita ser reelaborado, a partir de avaliações realizadas pela comunidade escolar. Fullan (1993) salienta que as mudanças e reformas não devem se prender a execução minuciosa do programa previsto, mas buscar desenvolver capacidades individuais e coletivas, sem perder de vista as suas finalidades educativas e as transformações que a evolução do contexto requer.

Entendendo que mudanças são necessárias ao PPP, o processo de reestruturação deve ser interno. A respeito dessa avaliação nas instituições abordadas, nota-se que é realizada à medida que são detectadas falhas no processo ou ao término do ano letivo, em que são retirados pontos que não deram certo e, inclusos os que se fizerem importantes.

Movimento, Porto Alegre, v. 17, n. 01, p. 77-94, janeiro/março de 2011. 
Nesse processo de avaliação analisam-se os resultados da própria organização do trabalho pedagógico, e se exige que os professores estejam plenamente envolvidos com o PPP da escola, sensíveis ao diálogo crítico com a realidade e com os alunos, suas necessidades e interesses, e sempre atentos à dimensão cultural das práticas corporais de movimento.

Dessa forma, o PPP se coloca como fundamental ao sistema organizacional de determinada instituição, na medida em que apresenta as mediações práticas necessárias à ação educacional. A concretização das propostas acontece quando os educadores dão conta de atribuir sentidos/significados às suas atividades cotidianas. Nesse momento, nas palavras de Severino (2008), é que as ações pedagógicas dos educadores se tornam educacionais, pois a educação só se efetiva se estiver impregnada de finalidades políticas, associadas aos conceitos de um projeto social, capaz de conferir significação ao processo humanizador.

Ao questionarmos aos pesquisados acerca do significado do PPP e sua importância para a educação, percebemos o reconhecimento do valor do projeto para a instituição escolar, sendo que, numa análise mais minuciosa, sabemos que isso não significa que as propostas preconizadas estejam sendo materializadas. Os depoimentos abaixo evidenciam as atribuições dadas por cada grupo confiadas ao PPP no âmbito escolar.

Ele é fundamental para que tudo ocorra, dentro de uma estrutura política e funcional, tendo relação com tudo o que acontece na escola. (Coordenação Pedagógica).

O PPP é importante, porque direciona nosso trabalho e metas a cumprir. Se não tivermos uma diretriz pra cumprir, alguma coisa acaba não dando certo. (Professor das demais áreas).

É importante porque define a formação de cidadãos. O projeto vai organizar como vamos por em prática o nosso trabalho, para que consigamos ajudar os alunos a perceber que ele faz parte do mundo, como atuante. (Professora de Educação Física).

Movimento, Porto Alegre, v. 17, n. 01, p. 77-94, janeiro/março de 2011. 
Diante do exposto, é possível refletir o PPP como ferramenta que possibilita preencher lacunas deixadas pelo distanciamento entre o conhecimento científico e a realidade dos alunos, abrindo espaço a ações interdisciplinares, que poderão contribuir com um ensino mais significativo. Para Japiassu (1976), por meio da interdisciplinaridade, se permite incorporar os resultados de várias disciplinas, tomando-lhes de empréstimo esquemas conceituais de análise, a fim de fazê-lo integrar, depois de havê-lo comparado e julgado.

A interdisciplinaridade auxiliará, de certa forma, na aplicabilidade do PPP no momento real de sala de aula, em que, a partir do trabalho de professores, alunos e toda a comunidade escolar, com a compreensão e inter-relacionamento entre as disciplinas, resultará em um planejamento expressivo que Gandin (1999) elucida ser por meio dele que se desenvolve um conjunto de modelos, processos, instrumentos e técnicas para dar importância ao conhecimento coletivo.

Ao questionar os professores se existe aplicabilidade dos objetivos e metas planejados no PPP, a maioria, revela que segue tendências, sendo elaboradas com alterações de acordo com a situação de cada turma. Outros argumentam que na tentativa de aplicar o projeto em todas as ações escolares, os focos da disciplina se perdem, às vezes, por falta de um fio condutor comum ou "incompatibilidade" entre o conteúdo a ser ensinado e a conduta metodológica estruturada no PPP. Freire (1996) ressalta que para criar as condições apropriadas no processo de ensino-aprendizagem se faz necessário a presença de educadores e educandos criadores, instigadores, inquietos, curiosos, humildes e persistentes.

Destaca-se que mesmo com a dificuldade na aplicação do PPP em todo contexto escolar, existe o acompanhamento da coordenação no desenvolvimento das aulas e dos semestres, tanto na rede estadual, como na municipal. A maior parte dos professores assinala que este acompanhamento é realizado, mediante visitas em sala de aula, acompanhamento do livro didático, conversas e orientações durante a hora-atividade.

Por fim, o presente estudo fortalece a visão de como é importante a reflexão sobre o que, o porquê e o como ensinar. Essa

Wovimento, Porto Alegre, v. 17, n. 01, p. 77-94, janeiro/março de 2011. 
reflexão solicita o conhecimento das Diretrizes Curriculares Nacionais atrelados a elementos políticos, sociais e econômicos. Nesse contexto se faz necessário refletir, discutir e avaliar a missão da escola; buscando quais são os objetivos da aprendizagem; como os conteúdos trabalhados se relacionam com estes objetivos; e examinar como os alunos estão avaliando e sendo avaliados neste processo. Por meio destas inter-relações que se ponderam os resultados do projeto, analisando se está sendo adequado ou requer modificações. É importante também, que se analise a questão do tempo, do espaço e dos recursos disponíveis. Com o planejamento, se concretiza a autonomia da escola e se inicia o processo de construção de sua identidade.

\section{ConCLUSÃo}

As incursões teóricas realizadas tiveram por finalidade demonstrar a importância do PPP como documento que orienta as ações interventivas do campo educacional, para, num próximo momento, relacioná-la com a pesquisa de campo. Objetivamos perceber como vêm sendo entendido e considerado no cotidiano da escola, buscando compreender como ocorre a participação da equipe escolar e da comunidade, no processo de elaboração e aplicação.

Nesse sentido, contemplaram-se por meio de relatos dos atores sociais envolvidos, alguns pontos relevantes do PPP e sua aplicação no ambiente escolar, entendendo que, os debates em torno do documento, são de grande valor para o delineamento do processo de ensino aprendizagem. Constatamos que o entendimento acerca do PPP é consistente, visto que a maioria dos entrevistados compreende seus aportes legais como fundamentais ao processo, buscando realizar a elaboração coletiva, a partir de uma gestão democrática, em que os interessados relacionam a realidade dos alunos, com os conteúdos estabelecidos, com intuito de promover a aquisição do conhecimento.

Em outra instância, percebemos que o reconhecimento do PPP como norteador das ações educacionais está acontecendo, afinal a comunidade escolar, o considera importante na orientação dos traba-

Movimento, Porto Alegre, v. 17, n. 01, p. 77-94, janeiro/março de 2011. 
lhos desenvolvidos. No entanto, a dificuldade está em sua extrapolação para viés prático, os educadores afirmam que, por vezes na necessidade de cumprir conteúdos adotam procedimentos extremamente técnicos.

Sabendo que toda mudança abarca certa instabilidade, uma vez que, mudar significa ir além de algo já conhecido, é possível discutir porque, no contexto escolar, essa questão se sobressai. Os professores, muitas vezes, sabem do que trata o documento, participam da sua elaboração, mas não o experienciam na prática, se mantendo em condutas antes estabelecidas. Trata-se de uma aversão a reflexões sobre determinada situação, objetivando modificá-la. Ocorre, assim, à manutenção de esquemas didáticos, fechando a possibilidade de explorar as peculiaridades dos envolvidos.

Essas diferenças poderão ser trabalhadas significativamente, quando, os educadores não se limitarem a desenvolver conteúdos, somente, a partir do que conhecem e reconhecem, mas também, daquilo que é desconhecido para eles. É com discussões/reflexões, e construção coletiva do PPP que se revelam diferentes pontos de vista, importantes a constituição de concepções de sujeitos e sociedade que se deseja formar.

Diante dessa situação, entendemos que o PPP deve extrapolar o campo documental, assumindo sua aplicabilidade no cotidiano escolar, em que a comunidade e corpo docente trabalhem em conjunto, em busca da humanização e apropriação do conhecimento, com o intuito de garantir a formação de seres plenos, capazes de atuar e, até mesmo, transformar a realidade em que vivem. Por meio dele se descobrem possibilidades de potencializar um ensino de qualidade e contribuir com a autonomia da escola. Aspectos esses que não se efetivaram nos discursos apresentados pelos entrevistados de forma geral.

Outra questão a ser lembrada, é que questionamentos em torno do projeto devem ser constantes, repercutindo em revisões e reformulações, para a adequação às modificações da realidade em que se insere $\mathrm{e}$, conseqüentemente, para a estruturação do ensino às necessidades dos educandos. Dessa forma, não se tem uma educação desconexa das finalidades propostas.

Movimento, Porto Alegre, v. 17, n. 01, p. 77-94, janeiro/março de 2011. 
Nesse estudo, nos deparamos com tal paradoxo, professores e equipe pedagógica afirmam ter conhecimento acerca das especificidades do PPP e suas contribuições, mas, ao nos remetermos à sistematização na prática, percebemos que, muitas vezes, essa se torna inconsistente, ou em outra instância, inexistente, notadamente, quando não se explora grande gama de conteúdos, associada à diversidade de alunos existente. Em especial, ao abordarmos a Educação Física, no que tange à escolha e tratamento dos conteúdos, esses devem abranger/trabalhar com componentes da cultura corporal, já que a área do conhecimento, busca por meio das práticas corporais, desenvolver o processo de aquisição do conhecimento, sistematizado que eduque e contribua efetivamente para o processo de construção de identidade dos sujeitos.

Na maioria das escolas estudadas, o PPP vem sendo elaborado e revisado por toda a comunidade educacional. Visualizamos o quadro como indispensável a mudanças expressivas no sistema de ensino. Contudo, esse se constitui apenas como primeiro passo para a transformação da realidade educacional. Muito ainda precisa ser trabalhado, analisado e discutido pelos membros que a constituem. Uma próxima etapa seria pensar na elaboração de ações interventivas que transformem os pontos ordenados em ações concretas, lembrando que devem se tratar de procedimentos que promovam a prática pedagógica coletiva e não de fórmulas pré-determinadas.

O PPP, portanto, não pode ser arquivado ou enviado às autoridades educacionais como simples tarefa burocrática. Após sua constituição, deve ser efetivado e vivenciado, como processo educativo da escola. O PPP só alcançará seus objetivos se solidificado na coletividade, de maneira que a consciência do significado de cada mudança se faça presente, com todos os componentes da escola unidos na construção do seu desenvolvimento. A autonomia será o meio de transformação, não eximindo a necessidade de prestar contas à sociedade, pois esse diálogo é imprescindível ao sucesso da ação educativa e, à composição de uma nova realidade, mais justa e humana.

Movimento, Porto Alegre, v. 17, n. 01, p. 77-94, janeiro/março de 2011. 
Political pedagogical project:development andimplementation in maringá public schools

Abstract :This research aimed to understand how does the participation of staff and school community of twenty public schools of Maringá, in the drafting and implementation of political pedagogical project. Were used document analysis and semi-structured interviews with team teaching, physical education teachers and other disciplines. There was a paradox between the development and implementation of political pedagogical project within the school environment. Teachers and pedagogical staff claim to have knowledge about the specifics of the political pedagogical project and their contributions, but the systematization and applicability become inconsistent, or nonexistent, due to differences and difficulties presented in context.

Keywords: Project formulation. Education. Professional autonomy.

Proyecto político pedagógico: desarrollo y aplicación en las escuelas públicas maringa

Resumen: Esta investigación tuvo como objetivo comprender cómo se és la participación del equipo y de la comunidad escolar de veinte escuelas públicas de Maringá, en la elaboración y ejecución del proyecto político pedagógico. Los archivos fueran utilizados como análisis documental así cómo entrevistas semiestructuradas con los equipos docentes, profesores de educación física y otras disciplinas. Hubo una paradoja entre el desarrollo y ejecución de proyectos de política educativa en el entorno escolar. Los maestros y personal de la pedagogía reclamo que conoce los detalles del proyecto político pedagógico y sus contribuciones, pero la sistematización y la aplicabilidad es inconsistente, o inexistente, debido a las diferencias y dificultades que se presentan en el contexto.

Palabras clave: Formulación de proyectos. Educación. Autonomía profesional.

\section{REFERÊNCIAS}

BARDIN, L. Análise de conteúdo. Lisboa: Edições 70, 1977.

BARTHOLO, M F. A construção do conhecimento e o projeto político- pedagógico da educação física. Pensar a Prática, Goiânia, v. 3, p. 53-64, jul./jun. 2000.

Movimento, Porto Alegre, v. 17, n. 01, p. 77-94, janeiro/março de 2011. 
BRASIL. Diretrizes e Bases da Educação Nacional. Lei n 9.394/1996, de 20 de dezembro de 1996. Diário Oficial da União. Brasília, DF, 23 dez. 1996.

FREIRE, P. Pedagogia da autonomia: saberes necessários à prática educativa. 13. ed. Rio de Janeiro: Paz e Terra, 1996.

Pedagogia da esperança: um reencontro com a Pedagogia do oprimido. 9. ed. Rio de Janeiro: Paz e Terra, 2002.

Pedagogia da autonomia. 30.ed.. São Paulo: Paz e Terra ,2004.

FULLAN, M. Change Forces: Probing the Depths of Educational Reform. London: Falmer, 1993.

GADOTTI, M. Pressupostos do projeto pedagógico. In: MEC, Anais da Conferencia Nacional de Educação para todos. Brasilia-DF, 1997.

Avaliação educacional e Projeto Político Pedagógico in: SEMINÁRIO INTERNACIONAL ITINERANTE DE EDUCADORES I. Alegrete e Uruguaiana, 1999. Disponível em: http://www.paulofreire.org/pub/Institucional/MoacirGadottiArtigosIt0005/Avali_educacional_PPP.pdf. Acesso em 15 de Setembro de 2010.

GANDIN, D. Temas para um projeto político pedagógico. Petrópolis, RJ: Vozes, 1999.

JAPIASSU, H. Interdisciplinaridade e patologia do saber. Rio de Janeiro: Imago, 1976.

LIBÂNEO, J.C. Didática. São Paulo: Cortez, 1992

MARQUES, M. O. Escola, aprendizagem e docência: imaginário social e intencionalidade política. In: VEIGA, I. P. A. (Org.). Projeto Político-Pedagógico: uma construção possível. 17. ed. Campinas: Papirus, 1995. p. 143-156.

MELLO, G.R N. Educação escolar brasileira: o que trouxemos do século XX? Porto Alegre: Artmed, 2004.

MILES, M.B.; HUBERMAN, A. M. Qualitative data analysis: an expanded Sourcebook. California: Sage, 1994.

MOREIRA, E.C. Educação Física escolar: desafios e propostas. Jundiaí: Fontoura, 2004

PINHEIRO, M. E. A ação coletiva como referencial para a organização do trabalho pedagógico. In: VEIGA, I. P. A.; RESENDE, L. M. G. (org.) Escola: espaço do projeto político-pedagógico. Campinas: Papirus, 1998.

SEVERINO, A. J. Seminário de Planejamento das Ações Pedagógicas nas Escolas da Rede Estadual, 2008. Disponível em: http://www.educacao.pe.gov.br/ diretorio/proj_pedag_2.pdf. Acesso em: 12 de setembro de 2010.

SILVEIRA, G.C.F.; PINTO, J.F.. Educação Física na perspectiva da cultura corporal: uma proposta pedagógica. Revista Brasileira de Ciências do Esporte. Campinas, v.22, n.3, p.137-150, 2001.

Mavimento, Porto Alegre, v. 17, n. 01, p. 77-94, janeiro/março de 2011. 


\section{Artifor Orifinais Amauri Aparecido Bássoli et al.}

TRIVIÑOS, A. N. S. Introdução à pesquisa em ciências sociais: a pesquisa qualitativa em educação. São Paulo: Atlas, 1987.

VASCONCELLOS, C.S. Planejamento-Projeto de ensino-aprendizagem e projeto político pedagógico. 14. ed. São Paulo: Libertad,2005.

VEIGA, I.P.A. "Escola, currículo e ensino". In: I.P.A. Veiga e M. Helena Cardoso (org.) Escola fundamental: Currículo e ensino. Campinas, Papirus,1991.

. Projeto político-pedagógico da escola: uma construção possível. 11. ed. Campinas: Papirus, 1995.

Recebido em: 20.09.2010

Aprovado em: 13.02. 2011

Movimento, Porto Alegre, v. 17, n. 01, p. 77-94, janeiro/março de 2011. 